\title{
Assessment of the Immunomodulatory Role of Dydrogesterone in Preventing Pregnancy Loss in Threatened Abortion
}

\author{
Zakia M Ibrahim ${ }^{1}$, Mamdouh E Said ${ }^{1}$, Khaled M El Nahas ${ }^{1}$, Soha E Younes ${ }^{2}$, Tamer Yehia M Ali ${ }^{1}$ and Omima \\ T Taha ${ }^{1 *}$ \\ ${ }^{1}$ Department of Obstetrics and Gynecology, Faculty of Medicine, Suez Canal University \\ ${ }^{2}$ Department of Clinical Pathology, Faculty of Medicine, Suez Canal University
}

*Corresponding author: Omima T Taha, Lecturer of Obstetrics and Gynecology, Department of Obstetrics and Gynecology, Faculty of Medicine, Suez Canal University, Ismailia, Egypt.

Received Date: March 04, 2020

Published Date: March 17, 2020

\begin{abstract}
Objective: To assess the immunomodulatory role of Dydrogesterone in preventing pregnancy loss in cases of threatened abortion.

Materials and methods: This were a prospective interventional study that included two groups each included 16 women. Group 1 included 16 pregnant women presented with symptoms of threatened abortion, and group 2 that included 16 health females with normal pregnancy. All of the studied females were subjected to complete clinical assessment. Laboratory assessment of serum levels of IL-4 (Marker of T-helper 2), IFN $\gamma$ (Marker of T-helper 1) and serum progesterone level were done for all participants. All women in group 1 were treated with certain doses of Dydrogesterone while women in control group were not allowed to use any form of progesterone. Participants were assessed for IL-4, IFN- $\gamma$ and progesterone after treatment. Also continuing pregnancy rates were calculated.

Results: Both groups were matched as regarding patients' characteristics and baseline parameters. Dydrogesterone has resulted in significant decrease of Th1/Th2 ratio with shift from Th1 predominance to Th2 predominance. Continuing pregnancy rate in the threatened abortion group was $93.8 \%$

Conclusion: Dydrogesterone is useful in the treatment of threatened abortion via modulating cytokine profile and causing shift in Th1/Th2 ratio for Th2 predominance and more specifically via decreasing level of Th1 markers as IF- $\gamma$.

Keywords: Dydrogesterone; Immunomodulation; Pregnancy; Threatened abortion
\end{abstract}

\section{Introduction}

Women with threatened abortion present with vaginal bleeding and/or uterine cramps while the cervix is still closed. This critical state may end up in spontaneous abortion or pregnancy may continue normally [1]. Tolerance of the maternal immune system to paternally derived fetal antigens is mandatory for a successful pregnancy. Disturbed immunological response towards the growing embryo may lead to pregnancy failure [2].

Several theories have been developed. One of these hypotheses is Th1/Th2 shift. A shift from the pro-inflammatory T-helper 1
(Th1) cell-dependent cytokines i.e. tumor necrosis factor- $\alpha$ (TNF$\alpha$ ), interferon- $\gamma$ (IFN- $\gamma$ ), interleukin (IL), IL-12, IL-18] to Th2-dependent anti-inflammatory cytokines (i.e. IL-3, IL-4, IL-5, IL-6, IL10, IL-13) seems to be typical for a successful pregnancy [2].

Shifting of the immune response towards the Th2 pattern would be of paramount benefit to the fetus, whereas dominance of pro-inflammatory Th1 cells may be hazardous. This hypothesis was supported by researches on different mouse strains with Leishmania infection during pregnancy, that lead to an anti-infectious Th1 response which was associated with failed implantation $[3,4]$. 
Progesterone has been proposed as a crucial immunomodulatory agent during early pregnancy, as it plays a role in the signaling chain of Th2-cell-dependent cytokines, and successful pregnancy is known to be a Th2-type phenomenon [4,5].

Dydrogesterone, an orally active progestogen, is similar to endogenous progesterone in its molecular structure and has a high affinity for progesterone receptors. It has the advantage of being devoid of androgenic side-effects in the mother (e.g. hirsutism, acne) or masculinizing effect on the female fetus $[4,5]$. The present study aimed to assess the immunomodulatory role of Dydrogesterone in preventing pregnancy loss in threatened.

\section{Materials and Methods}

After approval of our research ethics committee, this prospective interventional study was conducted in the obstetrics and gynecology department of Suez Canal University Hospitals from May 2017 to May 2019. The study was carried out among 32 pregnant females divided into two groups. Group 1 (study group) included 16 pregnant females who presented with symptoms of threatened abortion (bleeding, spotting and uterine cramps). Group 2 (control group) included 16 healthy females with normal healthy pregnancy with no symptoms of abortion and no history of habitual abortion as a reference group. Pregnant females with gestational age $>13$ weeks, chronic medical disorders, genital tract anomalies, history of use of progesterone prior to or during the study, and females with history of hypersensitivity to Dydrogesterone were excluded from the study.

\section{Methods}

All of the studied patients were subjected to the following:

Thorough obstetric history taking with emphasis on:

- $\quad$ First day of the last menstrual period

- $\quad$ Obstetric history

- Symptoms of threatened abortion (bleeding, spotting, uterine cramps)

Complete general and obstetric examination:

- $\quad$ Vital signs
- $\quad$ Height, weight and BMI

- Per vaginal examination for assessment of the cervical state

Abdominal/vaginal ultrasound: This was performed to all patients to evaluate gestational age of the fetus, to exclude multiple pregnancies and to confirm viability of pregnancy.

Laboratory measurement:

- Routine laboratory assessment (CBC, Rh factor, and urine analysis).

- Maternal serum levels of IL-4 were determined as a marker of T-helper 2 cell activity and values of IFN- $\gamma$ as a marker for T-helper 1 cell activity before and at the end of treatment in both groups. Serum IL-4 and IFN- $\gamma$ levels were measured by enzyme-linked immunosorbent assay (ELISA) technique

- $\quad$ Serum progesterone was determined by enzyme immunosorbent assay (ELISA) before and after treatment

Treatment:

- $\quad$ Group 1 (Threatened abortion group) received Dydrogesterone $40 \mathrm{mg}$ ( 4 tablets) as an initial dose then 10mg tablets every eight hours until symptoms subside (at least one week after symptoms subside)

- $\quad$ Group 2 (control group) participants were not allowed to use any progestogens prior to or during the study. They received placebo daily until they reached 13 weeks gestation.

- Both groups received their regular antenatal care according to NICE clinical guidelines [6]

- Ethical approval: This study was carried out after obtaining ethical approval on 01/04/2017 with a research number 3467\#.

\section{Results}

The two groups were matched as regard to age, special habits and consanguinity. There was no statistically significant difference between the studied groups as regard to gestational age, number of living children, parity and duration since last delivery (Table 1).

Table 1: Patients demographics and baseline characteristics.

\begin{tabular}{|c|c|c|c|c|c|c|}
\hline & & \multicolumn{2}{|c|}{ Threatened abortion } & \multicolumn{2}{|c|}{ Control group } & p-value \\
\hline \multirow[t]{2}{*}{ Age } & $\begin{array}{c}\text { Mean } \pm \\
\text { SD }\end{array}$ & \multicolumn{2}{|c|}{$29.4 \pm 6.5$} & \multicolumn{2}{|c|}{$26.06 \pm 4.9$} & \multirow{2}{*}{0.1} \\
\hline & Range & & & & & \\
\hline \multirow[t]{2}{*}{ Special habits } & No & 15 & $93.80 \%$ & 16 & $100 \%$ & \multirow{2}{*}{0.3} \\
\hline & Smoker & 1 & $6.30 \%$ & 0 & $0 \%$ & \\
\hline \multirow[t]{2}{*}{ Consanguinity } & No & 15 & $93.80 \%$ & 13 & $81.30 \%$ & \multirow{2}{*}{0.6} \\
\hline & Yes & 1 & $6.30 \%$ & 3 & $18.80 \%$ & \\
\hline
\end{tabular}




\begin{tabular}{|c|c|c|c|c|c|c|}
\hline \multirow[t]{2}{*}{ Gestational age } & \multirow{2}{*}{$\frac{\text { Mean } \pm \text { SD }}{\text { Range }}$} & \multicolumn{2}{|c|}{$9.13 \pm 1.6$} & \multicolumn{2}{|c|}{$9.19 \pm 2.01$} & \multirow{2}{*}{0.1} \\
\hline & & \multicolumn{2}{|c|}{$6-12$} & \multicolumn{2}{|c|}{$6-13$} & \\
\hline \multirow[t]{4}{*}{ Gravidity } & PG & 4 & $25 \%$ & 5 & $31.20 \%$ & \multirow{4}{*}{0.003} \\
\hline & G2-3 & 6 & $37.50 \%$ & 10 & $62.50 \%$ & \\
\hline & G 4-6 & 6 & $37.50 \%$ & 1 & $6.30 \%$ & \\
\hline & $G>6$ & 0 & $0 \%$ & 0 & $0 \%$ & \\
\hline \multirow[t]{3}{*}{ Parity } & NP & 4 & $25 \%$ & 5 & $31.20 \%$ & \multirow{3}{*}{0.2} \\
\hline & P $1-3$ & 10 & $62.50 \%$ & 11 & $68.80 \%$ & \\
\hline & P $4-5$ & 2 & $12.50 \%$ & 0 & $0 \%$ & \\
\hline \multirow[t]{3}{*}{ Number of abortions } & None & 13 & $81.30 \%$ & 14 & $87.50 \%$ & \multirow{3}{*}{0.001} \\
\hline & $1-2$ & 3 & $18.70 \%$ & 2 & $12.50 \%$ & \\
\hline & $\geq 3$ & 0 & $0 \%$ & 0 & $0 \%$ & \\
\hline \multirow[t]{3}{*}{ Number of living children } & None & 4 & $25 \%$ & 6 & $37.50 \%$ & \multirow{3}{*}{0.09} \\
\hline & $1-2$ & 8 & $50 \%$ & 10 & $62.50 \%$ & \\
\hline & $3-4$ & 4 & $25 \%$ & 0 & $0 \%$ & \\
\hline \multirow{2}{*}{$\begin{array}{c}\text { Duration since last } \\
\text { delivery }\end{array}$} & Mean \pm SD & \multicolumn{2}{|c|}{$3.8 \pm 2.6$} & \multicolumn{2}{|c|}{$2.6 \pm 1.2$} & \multirow[b]{2}{*}{0.1} \\
\hline & Range & \multicolumn{2}{|c|}{$0.3-10$} & \multicolumn{2}{|c|}{$0.6-4.5$} & \\
\hline \multirow[t]{3}{*}{ Nature of last pregnancy } & PG & 4 & $25 \%$ & 5 & $31.20 \%$ & \multirow{3}{*}{0.001} \\
\hline & Full term & 12 & $75 \%$ & 9 & $56.30 \%$ & \\
\hline & abortion & 0 & 0 & 2 & $12.50 \%$ & \\
\hline \multirow[t]{3}{*}{ CRL } & $<5 \mathrm{~mm}$ & 0 & $0 \%$ & 0 & $0 \%$ & \multirow{3}{*}{0.2} \\
\hline & 6-10mm & 3 & $18.80 \%$ & 0 & $0 \%$ & \\
\hline & $>10 \mathrm{~mm}$ & 13 & $81.20 \%$ & 16 & 100 & \\
\hline \multirow[t]{2}{*}{ Sub chorionic hematoma } & No & 14 & $87.50 \%$ & 16 & $100 \%$ & \multirow{2}{*}{0.3} \\
\hline & Yes & 2 & $12.50 \%$ & 0 & $0 \%$ & \\
\hline \multirow[t]{2}{*}{ Low lying GS } & No & 16 & $100 \%$ & 16 & $100 \%$ & \multirow{2}{*}{0.6} \\
\hline & Yes & 0 & $0 \%$ & 0 & $0 \%$ & \\
\hline
\end{tabular}

Table 2: IL-4, IF- $y$ and progesterone levels before after treatment at all groups of the study

\begin{tabular}{|c|c|c|c|c|}
\hline & & Threatened abortion & Control group & p-value \\
\hline \multirow[t]{3}{*}{$\mathrm{IL}-4$ (pg/ml) } & Before & $0.78 \pm 1.16$ & $0.34 \pm 0.31$ & 0.2 \\
\hline & After & $1.62 \pm 1.4$ & $0.97 \pm 0.62$ & \multirow{2}{*}{0.09} \\
\hline & $\mathrm{p}$-value & 0.07 & 0.001 & \\
\hline \multirow[t]{3}{*}{$\mathrm{IF}-\gamma(\mathrm{pg} / \mathrm{ml})$} & Before & $1.8 \pm 1.7$ & $1.01 \pm 1.4$ & 0.2 \\
\hline & After & $1.13 \pm 1.8$ & $0.18 \pm 0.4$ & \multirow{2}{*}{0.04} \\
\hline & p-value & 0.3 & 0.02 & \\
\hline \multirow[t]{3}{*}{ Th1/Th2 ratio } & Before & $7.5 \pm 8.6$ & $5.2 \pm 4.8$ & 0.4 \\
\hline & after & $1.6 \pm 4.6$ & $0.2 \pm 0.5$ & \multirow[b]{2}{*}{0.2} \\
\hline & $\mathrm{p}$-value & 0.02 & 0.003 & \\
\hline \multirow{3}{*}{$\begin{array}{l}\text { Serum proges- } \\
\text { terone level }\end{array}$} & Before & $28.9 \pm 9.1$ & $26.2 \pm 5.6$ & 0.3 \\
\hline & After & $45.9 \pm 16.7$ & $53.2 \pm 16.3$ & \multirow[b]{2}{*}{0.2} \\
\hline & p-value & 0.001 & 0.001 & \\
\hline
\end{tabular}


At $\leq 13$ weeks gestation, there was no statistically significant difference between control and study group regarding IL-4, IF- $\gamma$, Th1/Th2 ratio and serum progesterone level. Dydrogesterone ther- apy resulted in significant reduction of Th1/Th2 ratio with shift from Th1 predominance to Th2 predominance (Table 2).

Table 3: Continuing pregnancy rate and side effects among both study groups.

\begin{tabular}{|c|c|c|c|c|c|c|}
\hline \multirow{2}{*}{ Outcome } & \multicolumn{2}{|c|}{ Threatened abortion } & \multicolumn{2}{c|}{ Control group } & p-value \\
\cline { 2 - 6 } & Completed pregnancy & 15 & $93.80 \%$ & 16 & $100 \%$ & 0.4 \\
\hline \multirow{3}{*}{ Side effects } & Abortion & 1 & $6.30 \%$ & 0 & $0 \%$ & 0.8 \\
\cline { 2 - 7 } & Fetal Birth weight (Kg) & $2.9 \pm 0.8$ & & $3.1 \pm 0.5$ & & 0.8 \\
\cline { 2 - 7 } & Pre-eclampsia & 1 & $6.25 \%$ & 0 & $0 \%$ & 0.9 \\
\cline { 2 - 7 } & Ante partum hemorrhage & 1 & $6.25 \%$ & 1 & $6.25 \%$ & 0.7 \\
\cline { 2 - 7 } & Preterm labour & 1 & $6.25 \%$ & 0 & $0 \%$ & 0.2 \\
\hline
\end{tabular}

Only one patient of the threatened abortion group has been aborted. There was no statistically significant difference between both groups regarding fetal birth weight and obstetric complications. Only one case in the threatened abortion group had pre-eclampsia. Antepartum hemorrhage was recorded among one patient in the threatened abortion group and one patient in the control group and both cases were due to accidental hemorrhage (Table 3).

\section{Discussion}

Dydrogesterone is highly selective for progesterone receptors and lack estrogenic, androgenic, anabolic and corticoid properties which makes it different from other progestogens. It doesn't suppress the pituitary- gonadal axis making it a suitable management option for women with threatened miscarriage or any other pregnancy related disorders [7].

Like progesterone, Dydrogesterone is able to inhibit the production of Th- 1 cytokines and to up-regulate production of Th-2 cytokines, thus shifting the balance towards a pregnancy protective Th-2-dominated immune response [8].

In the present study, IL-4 has been evaluated as a marker of T-helper 2 cell activity and IF- $\gamma$ as a marker for T-helper 1 cell activity. Both were measured at the beginning and at the end of the study. Previous studies have evaluated markers as TNF- $\alpha$ (marker for T-helper 1 cell activity) and IL-12 (Marker for T-helper 2 cell activity) [9]. Another study has used more than one marker for each type of T-helper cells as in the study by Hudić, et al. [10]. They have used IL- 6 and IL-10 as markers for T-helper 2 cell activity and used both TNF- $\alpha$ and IF- $\gamma$ as markers for T-helper 1 cell activity. Also, the study by Raghupathy R, et al. [11] have used TNF- $\alpha$ and IF- $\gamma$ as markers for T-helper 1 cell activity and used IL-4 and IL-10 as markers for T-helper 2 cell activity.

Treatment of patients with threatened abortion with Dydrogesterone has resulted in $93.8 \%$ continuing pregnancy rate. Lower $(75.5 \%)$ but close to our results were reported by a previous study [12].

The results of the present study were also consistent with other studies that have shown that Dydrogesterone resulted in sig- nificantly higher continuing pregnancy rate compared to standard treatment in women with threatened abortion [13-15].

Many other studies have shown that treatment of women with threatened abortion with Dydrogesterone lowers abortion rate and increase continuing pregnancy rate [16-20].

The current study has also shown that there was a significant decrease in Th1/Th2 ratio at the end of the study compared to baseline value in both groups. This is due to shift from Th1 predominance at the beginning of pregnancy to Th2 predominance as pregnancy continues. There was no statistically significant difference regarding to neonatal outcome including birth weight and incidence of neonatal complications in both groups. A recent review of birth defects reported between 1977 and 2005 following maternal use of Dydrogesterone during pregnancy found no link between Dydrogesterone and birth defects [21].

Strengths and limitations: the sample included in the current study was small, large sample is recommended. We measured serum markers that reflect the immunomodulatory effect of Dydrogesterone on pregnancy. A comparison between different types of progestogens would be more informative.

\section{Conclusion}

Dydrogesterone was useful in treatment of threatened via modulating cytokine profile and causing shift in Th1/Th2 ratio for Th2 predominance more specifically via decreasing level of Th1 markers as IF- $\gamma$. Dydrogesterone was associated with increased rates of successful term pregnancies.

\section{Acknowledgement}

None.

\section{Conflict of Interest}

None.

\section{References}

1. Wahabi HA, Fayed AA, Esmaeil SA, Bahkali KH (2018) Progesterone for treating threatened miscarriage. Cochrane Systematic Reviews.

2. La Rocca C, Carbone F, Longobardi S, Matarese G (2014) The immunology 
of pregnancy: Regulatory $\mathrm{T}$ cells control maternal immune tolerance toward the fetus. Immunology Letters 162(1): 41-48.

3. Bansal AS (2010) Joining the immunological dots in recurrent miscarriage. The American journal of reproductive immunology 64(5): 307-315.

4. Walch KT, Huber JC (2008) Progesterone for Recurrent Miscarriage: Truth and Deceptions. Best Pract Res Clin Obstet Gynaecol 22(2): 375389.

5. El-Zibdeh MY (2005) Dydrogesterone in the reduction of recurrent spontaneous abortion. J Steroid Biochem Mol Biol 97(5): 431-434.

6. NICE guidelines (2017) Antenatal care for uncomplicated pregnancies / Clinical examination of pregnant woman.

7. Pandya MR, Gopeenathan P, Gopinath PM, Das SK, Sauhta M, et al. (2016) Evaluating the clinical efficacy and safety of progestogens in the management of threatened and recurrent miscarriage in early pregnancy- a review of the literature. Indian Journal of Obstetrics and Gynecology Research 3(2): 157-166.

8. Mekinian A, Cohen J, Alijotas-Reig J, Carbillon L, Nicaise-Roland P, et al. (2016) Unexplained recurrent miscarriageand recurrent implantation failure: is there aplace for immunomodulation? Am J Reprod Immunol 76(1): 8-28.

9. Raghupathy R, Szekeres- Bartho J (2019) Dydrogesterone and the immunology of pregnancy. Hormone molecular biology and clinical investigation 27(2): 63-71.

10. Hudić I, Szekeres-Bartho J, Fatušić Z, Stray-Pedersen B, DizdarevićHudić L, et al. (2011) Dydrogesterone supplementation in women with threatened preterm delivery- the impact on cytokine profile, hormone profile, and progesterone-induced blocking factor. J Reprod Immunol 92(1-2): 103-107.

11. Raghupathy R, Kalinka J (2008) Cytokine imbalance in pregnancy complications and its modulation. Frontiers in Bioscience 13: 985-994.
12. El-Zibdeh M (2002) Randomised clinical trial comparing the efficacy of dydrogesterone, human chorionic gonadotropin (hCG) or no treatment in the reduction of habitual abortion. Poster presentation. $10^{\text {th }}$ World Congress on the Menopause, Berlin, Germany.

13. Omar MH, Mashita MK, Lim PS, Jamil MA (2005) Dydrogesterone in threatened abortion: Pregnancy outcome. J Steroid Biochem Mol Biol 97(5): 421-425.

14. Czajkowski K, Sienko J, Mogilinski M, Bros M, Szczecina R, et al. (2007) Uteroplacental circulation in early pregnancy complicated by threatened abortion supplemented with vaginal micronized progesterone or oral dydrogesterone. Fertil Steril 87(3): 613-618.

15. Pandian RM, Adeeb N, Parampalam SD, Balanathan K, Yuzainov A, et al. (2009) Dydrogesterone in threatened miscarriage: a Malaysian experience. Gynecol Endocrinol 65(1): 47-50.

16. Kalinka J, Radwan M (2006) The impact of dydrogesterone supplementation on serum cytokine profile in women with threatened abortion. Am J Reprod Immunol 55(2): 115-121.

17. Pelinescu-Onciul D (2007) Subchorionic hemorrhage treatment with dydrogesterone. Gynecol Endocrinol 23(Suppl 1): 77-81.

18. El-Zibdeh MY (2009) Dydrogesterone support in threatened miscarriage. Gynecol Endocrinol 65(1): 43-46.

19. El-Zibdeh MY, Yousef LT (2009) Dydrogesterone support in threatened miscarriage Maturitas 65 Suppl 1: S43-S46.

20. Lee HJ, Park TC, Kim JH, Norwitz E, Lee B (2017) the influence of oral Dydrogesterone and vaginal progesterone on threatened abortions: a systematic review and meta-analysis. BioMed Research International.

21. Queisser-Luft A (2009) Dydrogesterone use during pregnancy: overview of birth defects reported since 1977. Early Hum Dev 85(6): 375-377. 